\title{
The Impact of COVID-19 on Plastic Surgery Training in the United Kingdom, Canada and Australia-A Cross-Sectional Study
}

\author{
Curtis R Budden ${ }^{1}$ Francesca Rannard ${ }^{2}$ Joanna Mennie ${ }^{2}$ Neil Bulstrode ${ }^{2}$ \\ ${ }^{1}$ Department of Surgery, University of Alberta, Edmonton, Canada \\ 2Department of Plastic Surgery, Great Ormond Street Hospital, \\ London, United Kingdom \\ Address for correspondence Curtis R Budden, MD MEd FRCSC, \\ Department of Surgery, University of Alberta, 8440112 ST NW, \\ Edmonton, T6G 2B7, Canada (e-mail: budden@ualberta.ca).
}

Indian J Plast Surg 2021;54:327-333.

\begin{abstract}
Keywords

- plastic surgery training

- COVID-19

- work restrictions

- lockdown

Background Surgical trainees worldwide have been thrust into a period of uncertainty, with respect to the implications COVID-19 pandemic will have on their roles, training, and future career prospects. It is currently unclear how plastic surgery trainees are being affected by COVID-19. This study examined the experience of plastic surgery trainees in Canada, the UK, and Australia to determine trainee roles during the early COVID-19 emergency response and how training changed during this time.

Methods A cross-sectional survey-based study was designed for plastic surgery trainees in the UK, Canada and Australia. In total, 110 trainees responded to the survey. Statistical tests were conducted to determine differences in responses, based on year of training and country of residence.

Results In total, 9.7\% (10/103) of respondents reported being deployed to cover another service. There was a significant difference between redeployment based on country $(p=0.001)$. Within the UK group, $28.9 \%$ of respondents were redeployed. For trainees not deployed, $95.5 \%$ (85/89) reported that there has been a reduction in operative volume. Ninety-seven (94.1\%) respondents reported that there were ongoing teaching activities offered by their program. The majority of trainees $(66.4 \%)$ were concerned about their training. There was a significant difference between overall concern and country $(p<0.05)$.

Conclusion In these unprecedented times, training programs in plastic surgery should be aware of the major impact that COVID-19 has had on trainees and will have on their training. The majority of plastic surgery trainees have experienced a reduction in surgical exposure but have maintained some form of regular teaching.
\end{abstract}

\section{Introduction}

COVID-19 has caused massive loss of life and disruption to our busy world. Surgical trainees worldwide have been thrust into this period of uncertainty, with respect to the implications COVID-19 pandemic will have on their roles, training, and future career prospects. All major governing bodies have helped guide local policy, with their position statements for training and surgical services to be offered during the pandemic. The Royal College of Surgeons of Edinburgh has acknowledged that trainees will be asked to step into roles outside those of their current training. ${ }^{1}$ The Royal College of published online September 16, 2021
DOI https://doi.org/ $10.1055 / \mathrm{s}-0041-1734569$ ISSN 0970-0358 (c) 2021. Association of Plastic Surgeons of India.

This is an open access article published by Thieme under the terms of the Creative Commons Attribution-NonDerivative-NonCommercial-License, permitting copying and reproduction so long as the original work is given appropriate credit. Contents may not be used for commercial purposes, or adapted, remixed, transformed or built upon. (https://creativecommons.org/licenses/by-nc-nd/4.0/).

Thieme Medical and Scientific Publishers Pvt. Ltd. A-12, 2nd Floor,

Sector 2, Noida-201301 UP, India 
Surgeons of Canada released a statement that "[the] impact to workload and day-to-day activities could be minimal for some and significant for others, with some effects including increases in patient load and redeployment of residents and staff to deal with patient surges, limitations in clinical activity due to a shift in priorities to acute COVID management, and the need to fill in for sick or absent colleagues." A similar statement was released by the Australia Society of Plastic Surgeons which outlined four specific implications of the pandemic on plastic surgery training. These are "the possibility that competencies may not be met and that time spent in training may be increased; the possibility that new applications to the training program will not be considered for the year beginning 2021; the final fellowship examinations have been cancelled in May by RACS and a decision on the September 2020 fellowship examination will be made in June; above all maintain self-safety utilizing PPE when consulting and performing procedures." ${ }^{3}$

Across various specialties, efforts are being made to explore how to maintain training and support for trainees during this global pandemic. ${ }^{4-13}$ It is currently unclear how plastic surgery trainees are being affected by COVID-19. Local guidelines and needs will mandate how doctors are deployed to manage the change in health care delivery. It has been expected that trainees obtain the necessary induction and support to safely fulfill these roles. Some surgical specialties have been able to keep trainees on their home service to provide ongoing emergency care. Other services, like plastic surgery, has seen a dramatic decrease in surgical cases; therefore, many trainees may be redeployed to cover surges in patients in other medical areas. The Royal College of Surgeons of Australia and England have supported the suspension of all elective surgery. As the curve is beginning to flatten in some areas of the world, elective surgery will be resuming at different rates. There has also been a shift in the delivery of teaching to trainees, the majority of which has become virtual. ${ }^{14}$ Research meetings have also been conducted virtually, which allows for trainees to continue their academic pursuits. ${ }^{15}$

This study examined the experience of plastic surgery trainees in Canada, the UK, and Australia to determine trainee roles during the COVID-19 emergency response and how training changed during this time. Secondary objectives were to determine trainees' level of concern regarding their future training.

\section{Methods}

A cross-sectional study was designed to capture the experience of plastic surgery trainees at all levels of training. All trainees were given the opportunity to participate. Three countries were selected, based on the experience of the research team and similarities in training models. The survey was generated, based on the research questions. It was then field tested with trainees in all three countries. The option to disagree with the question item responses was provided in the survey to capture opinions not directly presented. The online platform SurveyMonkey (SurveyMonkey
Inc, USA) was used to facilitate survey distribution and data collection. We held a focus group discussion to generate survey questions centered on the following themes: current training duties and experience, ongoing teaching activities, effect on employment and remuneration, and concerns for future training. Questions were checked for clarity of wording with a plastic surgeon outside the study. The survey was distributed via email contacts from the national plastic surgery societies of Canada and Australia. For the UK, it was distributed via the Plasta group email (a national trainee database). All respondents are enrolled in a national plastic surgery training program and are working in urban teaching hospitals. These trainees would have the potential to be treating COVID-19 positive patients. In total, 336 email accounts were delivered the survey. The response rate was $30.6 \%$. All responses were anonymous and identifiable only by a computer-generated identification code. The data was secured on a password-encrypted hard drive. No personally identifying information was collected. The online and hard drive passwords were not shared to enhance security. The collected data was not shared over any online network or internet connection. Given the time sensitive nature of the study, a 1-week interval was allowed before redistributing the survey. Data was assessed using parametric tests for within and between group frequency differences. Microsoft Excel (Microsoft, USA) and SPSS Version 26.0 (IBM Inc., USA) were used for statistical analysis.

\section{Results}

In total, 110 trainees responded to the survey. A total of 50 trainees in Canada, 38 trainees in the UK, and 21 trainees in Australia responded. There are five main sections to the questionnaire based on the item theme. These are as follows: (a) respondent demographics (b) current training duties and experience (c) ongoing teaching activities (d) effect on employment and remuneration, and (e) concerns for future training (Appendix 1).

\section{Respondent Demographics}

Of the total respondents, 103 identified as plastic surgery trainees. The current level of training varied among respondents. Twenty (19.4\%) identified as first year, 18 (17.5\%) as second year, 21 (20.4\%) as third year, 11 (10.7\%) as fourth year, $30(29.1 \%)$ as fifth year, and $3(2.91 \%)$ as fellows. There were no significant differences based on country.

\section{Current Training Duties and Experience}

Respondents were asked about their current work, details of any deployment, and self-perceived competence in their current role. In total, 9.7\% (10/103) of respondents reported being deployed to cover another service. The remaining $90.3 \%$ (93/103) were not deployed to other services. There was a significant difference between redeployment based on country ( $p=0.001$ ). Within the UK group, $28.9 \%$ of respondents were redeployed. Of those redeployed, there was a vast array of services being covered by plastic surgery trainees. These included intensive care (2\%), general surgery (5\%), 
neurosurgery (1\%), general adult internal medicine (3\%), subspecialty adult medicine (1\%), general pediatrics (1\%), subspecialty medical pediatrics (2\%), and other (3\%). These positions were equal in seniority (63.2\%) or junior to (36.8\%) their pre-COVID post. For those who have been redeployed, $53.6 \%$ stated they did not feel they had adequate training to their new role. When examined based on deployment, there was a significant difference in perceived competency in the current role. Fifty percent of trainees deployed to other services did not feel competent, whereas only $5.5 \%$ of trainees did not feel competent if still doing plastic surgery $(p<0.001)$.

For trainees not deployed, 95.5\% (85/89) reported that there had been a reduction in operative volume. An estimate of the operative reduction by respondents found that $43.8 \%$ (39/89) felt the volume was reduced by greater than $75 \%$, thirty percent (27/89) felt the reduction was between 50 to $75 \%$, and $13.5 \%$ (12/89) thought between 25 to $50 \%$.

\section{Ongoing Teaching Activities}

Ninety-seven (94.1\%) respondents reported that there were ongoing teaching activities offered by their program. Six respondents stated there was no regular teaching. Of those having regular teaching, the majority of teaching was occurring weekly (56/102) or daily (26/102). The teaching sessions were led by a range of instructors with varying combinations and levels of qualifications. - Table 1 summarizes the teaching findings of this study. When between country differences were examined, the UK respondents noted a significantly greater proportion of shorter teaching sessions compared with Canadian and Australian trainees ( $p<0.001,50 \%$ vs. $19 \%$ and $6.1 \%$ ). Canadian trainees have reported a higher

Table 1 Plastic surgery teaching during COVID-19 based on trainee survey responses (expressed as percentage of responses)

\begin{tabular}{|c|c|c|c|c|}
\hline & Canada & UK & Australia & $p$-value \\
\hline \multicolumn{5}{|l|}{ Is the local program offering teaching } \\
\hline Yes & $98.0(49 / 50)$ & $87.1(27 / 31)$ & $95.2(20 / 21)$ & 0.241 \\
\hline No & $2.0(1 / 50)$ & $12.4(4 / 31)$ & $4.8(1 / 21)$ & \\
\hline \multicolumn{5}{|l|}{ How often is the teaching } \\
\hline Daily & $38.0(19 / 50)$ & $16.1(5 / 31)$ & $9.5(2 / 21)$ & $<0.001$ \\
\hline Weekly & $48.0(24 / 50)$ & $58.1(18 / 31)$ & $66.7(14 / 21)$ & \\
\hline Monthly & - & $6.5(2 / 31)$ & $9.2(2 / 21)$ & \\
\hline Other & $14.0(7 / 50)$ & $6.5(2 / 31)$ & $14.3(3 / 21)$ & \\
\hline \multicolumn{5}{|l|}{ How long are the teaching sessions } \\
\hline 1 hour or less & $6.0(3 / 50)$ & $50.0(15 / 30)$ & $19.1(4 / 21)$ & 0.001 \\
\hline $1-2$ hours & $74.0(37 / 50)$ & $46.7(14 / 30)$ & $71.4(15 / 21)$ & \\
\hline $2-3$ hours & $16.0(8 / 50)$ & $3.3(1 / 30)$ & $9.5(2 / 21)$ & \\
\hline Greater than 3 hours & $4.0(2 / 50)$ & - & - & \\
\hline \multicolumn{5}{|c|}{ How would you rate the current amount of teaching } \\
\hline Too little & $18.0(9 / 50)$ & $26.7(8 / 30)$ & $9.5(2 / 21)$ & 0.343 \\
\hline About right & $70.0(35 / 50)$ & $60.0(18 / 30)$ & $90.5(19 / 21)$ & \\
\hline Too much & $10.0(5 / 50)$ & $6.7(2 / 30)$ & - & \\
\hline Unsure & $2.0(1 / 50)$ & $6.7(2 / 30)$ & - & \\
\hline \multicolumn{5}{|c|}{ Who is providing teaching (various combinations exist) } \\
\hline Trainee led & $74.0(37 / 50)$ & $36.7(11 / 30)$ & $38.1(8 / 21)$ & \\
\hline Local consultant (s)/attending (s) & $90.0(45 / 50)$ & $83.3(25 / 30)$ & $85.7(18 / 21)$ & \\
\hline Visiting/invited surgeon & $34.0(17 / 50)$ & $23.3(7 / 30)$ & $19.0(4 / 21)$ & \\
\hline Deanery-wide teaching (UK) & - & $36.7(11 / 30)$ & - & \\
\hline State-wide teaching (Australia) & - & - & $66.7(14 / 21)$ & \\
\hline Nationwide teaching (Canada) & $98.0(49 / 50)$ & - & - & \\
\hline Other & $8.0(4 / 50)$ & $10.0(3 / 30)$ & - & \\
\hline
\end{tabular}

a Based on Chi-square analysis of between country response differences 
proportion of daily teaching compared with those in the UK and Australia ( $p<0.05,38 \%$ vs. $16.1 \%$ and $9.5 \%)$.

\section{Effect on Future Employment and Remuneration}

When asked whether this pandemic has affected a future consultant position, 12/103 (11.7\%) responded yes. Twenty-six percent (27/103) stated that COVID-19 had affected their plans for future fellowship. This is dependent on year of training, as there was a significant difference in responses based on year $(p<0.005)$. Trainees in fifth year said their plans for fellowship were affected in 17/30 (56.7\%) and 3/3 fellow respondents said future fellowship plans were affected.

The overall work hours are different for trainees. Eighty-six percent (89/103) reported a change in work hours. The way in which the hours changed was quite variable, depending on the trainee. Overall, $35 \%$ of the responses indicated that there were less daytime hours. When exploring remuneration, $77.7 \%$ of respondents noted their pay was unchanged during the pandemic period. The pay was unchanged in $93.6 \%$ of cases where trainees working less hours and in $70.8 \%$ of trainees working more hours. This difference was statistically significant based on country of residence. Respondents in Australia are more likely to be remunerated for working extra hours, compared with those in Canada and the UK ( $p=$ $0.023,28.6 \%$ vs. 8.0 and $18.4 \%$ ).

\section{Concerns for Future Training}

Expectations of how COVID-19 would affect various aspects of the training were explored. The majority of trainees (66.4\%) are concerned about their training. There was a significant difference between overall concern and country. Trainees in Australia reported to be less concerned than those in Canada and the UK ( $p=0.023,33.3 \%$ vs. 72.0 and $76.3 \%$ ). There was a significant difference between the level of concern and year of training $(p<0.05)$. Those in their fifth year were less concerned that this pandemic period would change the length of the training program. Overall, $27.3 \%$ of trainees anticipate a change to the length of their program, whereas $41.8 \%$ did not anticipate a change and $30.9 \%$ were unsure. These are summarized in - Fig. 1.

\section{Discussion}

This study provides a snapshot of the current work and concerns of plastic surgery trainees in three countries during the COVID-19 pandemic. The first finding is that the majority of trainees have not been redeployed to cover other services. They are working on plastic surgery services but with a significant reduction in surgical volume. The UK and to a lesser extent the Canadian group were the only ones to report deployment to other specialties. This may be due to differences in how each country managed medical resources during the pandemic and the total number of severe COVID-19 cases. Those who have been redeployed experienced various levels of training in their new positions. Trainees in this study often reported that they did not receive adequate training in their new role and reported less competency in their new role. A published statement of the General Medical Council states that "if you are required to work in a less familiar clinical setting or at the limits of your competence for your stage of training, your employer should provide appropriate induction and clinical supervision." ${ }^{16}$ The details of induction for a new role was not explored by this study. It is known that trainees in orthopedic surgery have reported that they too have been covering other specialties during this pandemic time. ${ }^{17}$ With a reduction in surgical volume, the orthopedic

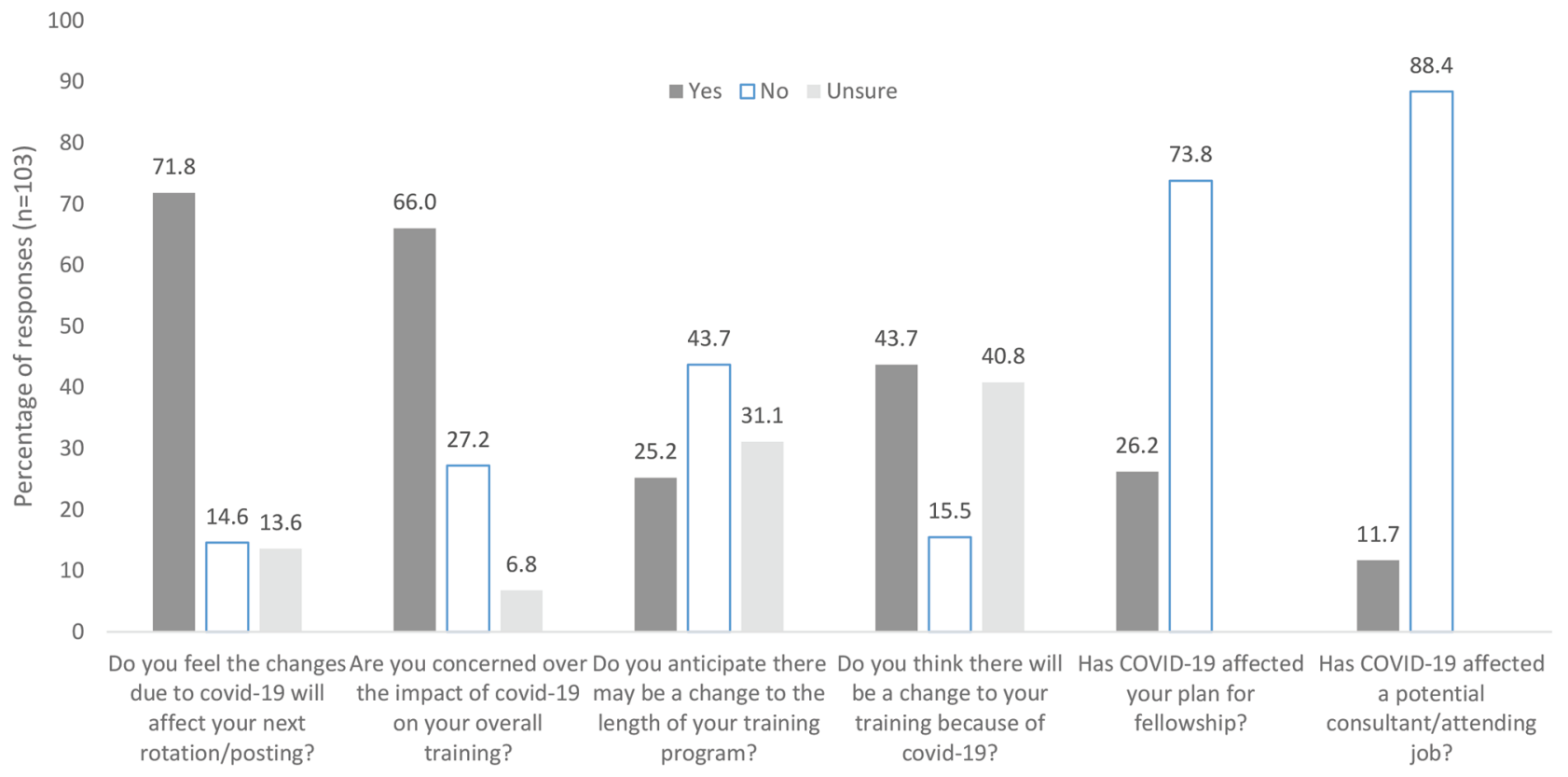

Questionnaire Items pertaining to trainee opinions over future training

Fig. 1 Trainee responses, in percentage, to questionnaire items pertaining to their opinions of the effects of COVID-19 on training. 
surgery team at Rush University Medical Center have advocated that now is the time to utilize teaching adjuncts to augment learning. ${ }^{10}$ Their group has published on a sample teaching/independent study schedule currently used by trainees during COVID-19. It emphasizes the importance of self-study and research as a way to enhance learning. This is being coupled with online group teaching to review concepts. Overall, plastic surgery trainees are still being exposed to problems relevant to their specialty training, albeit at a lower volume during the pandemic period.

The second major finding is that the majority of trainees are still receiving some form of regularly scheduled, formalized teaching. Many reports of adjuncts to medical teaching during COVID-19 have been published, but it appears that plastic surgery respondents in this study are still receiving some form of didactic teaching on a regular basis. ${ }^{18}$ This is encouraging and speaks of the dedication to medical education. It is not clear from this study whether this is a change in the pre-COVID-19 teaching schedule. The majority of respondents noted weekly teaching sessions lasting 1 to 2 hours. At Great Ormond Street Hospital, plastic surgery teaching is occurring once a week under the tutelage of a combination of consultants and invited speakers. Trainees are also encouraged to participate in additional local webinars for plastic surgery trainees which take place multiple days per week. Attendance of these sessions has risen due to the use of teleconferencing technologies combined with the reduction in surgical workload, and it has been possible to invite national and international speakers to present. This is a positive outcome, which would be encouraged in the future. The frequency of the monthly departmental meeting has been increased to a weekly event and made open to all of the administration, nursing and clinical teams in order to not only cascade important information and updates but also discuss the concerns and anxieties of all members. This has been a useful forum for the team to raise and highlight issues which have been addressed and whose solutions have been found. A study conducted in India found that there has been an increase in the number of online teaching sessions. ${ }^{15}$ According to the authors, having too many webinar options can create a difficult choice for residents as to which lectures to attend.

Although our study found variations in the number of trainees reporting redeployment, a significant reduction in surgical volume was noted by all. This loss in operative exposure may have an effect on training. ${ }^{19}$ In total, 66\% of respondents stated they were concerned about the impact COVID-19 would have on their training. There were also significant disparities about whether training would be extended along with disparities in concerns among countries. What is clear from this survey is that trainees are uncertain about the future impact. This level of uncertainty can cause psychological distress, and it would be prudent for programs to ensure the mental well-being of trainees during this time. ${ }^{20,21}$ Unfortunately, the fallout from COVID-19 will likely be for many more months. It is evident from our survey that trainees still need clarity as to the steps that will be put in place to ensure this, and also require united guidance from colleges in terms of what the future holds.

An additional finding of the study is that senior trainees seem have to be affected to a greater extent compared with junior trainees, based on the parameters of the questionnaire. They are more likely to have a change in plan for fellowship and be affected while applying for a consultant position. This was also found in India where $56.5 \%$ of trainees were concerned that jobs and fellowships may be compromised due to COVID-19. ${ }^{15}$ It is important that postgraduate medical education (PGME) departments have or develop a strategy to assist trainees whose transition to a higher level is now affected. If more trainees are not advancing to a higher post, it could result in further work force issues and increase competition for future consultant postings.

\section{Limitations}

This study was conducted to obtain a snapshot of trainee experience during a pandemic. Given the time-sensitive nature of the data collection, a short collection period likely limited our response rate. The delivery methods to the trainees were potentially more effective in some countries, compared with others given access to trainee contact information. To enhance anonymity of the collected data, gender was not included; gender bias therefore cannot be ruled out in interpretation of our results. Further questionnaire validity and reliability testing will be of benefit for any future comparative analysis.

\section{Future Directions}

Further studies should continue to track the educational experience of trainees during this period. The experience of having no or limited elective surgeries due to COVID-19 may, for example, yield a significant increase in exposure after COVID-19 restrictions are lifted. This could possibly negate any lost operative experience. The significance of redeployment on training may also be examined in those affected.

\section{Conclusion}

In these unprecedented times, training programs in plastic surgery should be aware of the major concern from trainees that COVID-19 has had and will have on their training. The majority of plastic surgery trainees have experienced a reduction in surgical exposure but have maintained some form of regular teaching. Looking to the future, programs should be transparent and offer a strategy for trainees to meet their educational needs. Governing bodies will likely ask trainees to continue to be flexible and adapt to changes in our existing educational model. Training programs would benefit from regular assessments to assess whether this modification in training has affected educational outcomes.

\section{Disclosures}

None.

\section{Funding}

None. 


\section{Conflict of Interest}

None.

\section{References}

1 Royal College of Surgeons Edinburgh. Statement on COVID-19 and its effect on surgical training. Available at: https://www.rcsed.ac.uk/news-public-affairs/news/2020/ march/statement-on-covid-19-and-its-effect-on-surgicaltraining. Accessed April 28, 2020

2 Royal College of Physicians and Surgeons of Canada. Impact of COVID-19 on residency education. Available at: http://www. royalcollege.ca/rcsite/documents/about/covid-19-impact-residency-education-e. Accessed May 3, 2020

3 Snapshot. Available at: https://plasticsurgery.org.au/protecting-plastic-surgeons-trainees-covid-19/. Accessed May 3, 2020

4 Kwon YS, Tabakin AL, Patel HV, et al. Adapting urology residency training in the COVID-19 era. Urology 2020;141:15-19

5 DeFilippis EM, Stefanescu Schmidt AC, Reza N. Adapting the educational environment for cardiovascular fellows-in-training during the COVID-19 pandemic. J Am Coll Cardiol 2020;75(20):2630-2634

6 Rakowsky S, Flashner BM, Doolin J, et al. Five questions for residency leadership in the time of COVID-19: reflections of chief medical residents from an internal medicine program. Acad Med 2020;95(8):1152-1154

7 Berg DD, Divakaran S, Stern RM, Warner LN. Fostering meaning in residency to curb the epidemic of resident burnout: recommendations from four chief medical residents. Acad Med 2019;94(11):1675-1678

8 Mian A, Khan S. Medical education during pandemics: a UK perspective. BMC Med 2020;18(1):100

9 Langer PD, Bernardini FP. Oculofacial plastic surgery and the COVID-19 pandemic: current reactions and implications for the future. Ophthalmology 2020;127(9):e70-e71

10 Kogan M, Klein SE, Hannon CP, Nolte MT. Orthopaedic education during the COVID-19 pandemic. J Am Acad Orthop Surg 2020;28(11):e456-e464
11 Comer BT, Gupta N, Mowry SE, Malekzadeh S. Otolaryngology education in the setting of COVID-19: current and future implications. Otolaryngol Head Neck Surg 2020;163(1):70-74

12 Codispoti CD, Bandi S, Moy JN, Mahdavinia M. Running a virtual allergy division and training program in the time of COVID-19 pandemic. J Allergy Clin Immunol 2020;145(5):1357-1359

13 Stambough JB, Curtin BM, Gililland JM, et al. The past, present, and future of orthopedic education: lessons learned from the COVID-19 pandemic. J Arthroplasty 2020;35(7S) :S60-S64

14 Dash S, Das R, Saha S, Singhal M. Plastic surgeons and COVID-19 pandemic. Indian J Plast Surg 2020;53(2):191-197

15 Kumar S, More A, Harikar M, Dharini 1. The impact of COVID-19 and lockdown on plastic surgery training and practice in India. Indian J Plast Surg 2020;53(2):273-279

16 Snapshot. Available at: https://www.gmc-uk.org/ethical-guidance/ethical-hub/covid-19-questions-and-answers\#Workingsafely. Accessed May 6, 2020

17 Liang ZC, Ooi SB. COVID-19: Aa Singapore orthopedic resident's musings in the emergency department. Acad Emerg Med 2020;27(4):349-350

18 Coe TM, Jogerst KM, Sell NM, et al. Practical techniques to adapt surgical resident education to the COVID-19 era. Ann Surg 2020;272(2):e139-e141

19 Pearce WH, Parker MA, Feinglass J, Ujiki M, Manheim LM. The importance of surgeon volume and training in outcomes for vascular surgical procedures. J Vasc Surg 1999;29(5):768-776, discussion 777-778

20 Maher A, Rouprêt M, Misrai V, et al. COVID-19 outbreak situation and its psychological impact among surgeon in training in France. World J Urol 2020;(e-pub ahead of print). doi: $10.1007 / \mathrm{s} 00345-020-03207-\mathrm{x}$

21 Shaw SCK. Hopelessness, helplessness and resilience: The importance of safeguarding our trainees' mental wellbeing during the COVID-19 pandemic. Nurse Educ Pract 2020;44:102780 


\section{Appendix 1: Questionnaire items}

1. Are you a plastic surgery trainee?

2. In which country are you currently practicing?

3. What is your current level of training?

4. Do you feel the changes due to COVID-19 will affect your next rotation/posting?

5. Are you concerned over the impact of COVID-19 on your overall training?

6. Do you anticipate there may be a change to the length of your training program?

7. Has COVID-19 affected your plan for fellowship?

8. Has COVID-19 affected a potential consultant/attending job?

9. Are you currently deployed to cover a different service than plastic surgery (i.e., covering ICU during c COVID-19 pandemic)?

10. If still doing plastic surgery, is the volume of cases decreased?

11. If so, by how much would you estimate a decrease in operative cases?

12. Are your current work hours different since COVID-19?

13. Is your current training program offering ongoing teaching in plastic surgery?

14. How would you rate the current level of teaching you are receiving?

15. How often are the teaching sessions?

16. If there is teaching, how long are the sessions?

17. Who is providing the teaching? (choose all that apply)

18. If you are working more hours or more weekend days, are you being remunerated for any additional hours/increase in weekend work?

19. If your hours/weekend work has decreased, has your pay also been decreased?

20. Are you still performing surgical procedures?

21. What is the nature of the surgical procedures (please choose all that apply)

22. If not doing plastic surgery, which services are you covering? (please choose all that apply)

23. Do you feel competent in your current position?

24. Do feel equally as competent in what you are doing now versus pre-COVID-19?

25. If redeployed to another position, did you receive adequate training in your current redeployed position?

26. If you are redeployed, describe the seniority level of your current post versus pre-COVID-19.

27. Do you think there will be a change to your training because of COVID-19?

28. Has the amount you are paid changed during COVID-19?

29. How have your work hours changed (choose all that apply)? 